\section{Keep a way open for tailored treatments}

Two documents with crucial implications for the future of personalized medicine were released last month: a report from the US Institute of Medicine (IOM) emphasizing the importance of open data sharing (see go.nature.com/ hofgoc) and a US Supreme Court decision ruling against two patents (see go.nature.com/ lj9kyl), which could have the opposite effect.

This creates a quandary for companies aiming to pursue personalized treatments or methods, because those that adopt the IOM's advice to share their information now face greater hurdles to protecting their contributions through patents.

Companies should not be discouraged from exploring personalized medicine - to do so would deny society the benefit of tailored therapies. Likewise, firms that prefer to keep personalization algorithms secret will hinder scientific progress.

Instead, companies could sell value-added products that use open algorithms and statistical models - much like Google and IBM, for example, which have embraced open-source software.

To deliver effective treatments to patients, we need to find a way to reward companies for investing in personalized medicine while allowing the scientific community to advance knowledge rapidly.

Jeffrey T. Leek, Roger D. Peng Johns Hopkins Bloomberg School of Public Health, Baltimore,

Maryland, USA.

jtleek@gmail.com

R. Reeves Anderson Arnold \&

Porter LLP, Washington DC, USA.

\section{Boost water safety in rural China}

The world is well on its way to meeting the Millennium Development Goal to halve by
2015 the proportion of people who in 1990 had no sustainable access to safe drinking water (Nature 483, 128-129; 2012). But more resources are still needed to improve water quality in China, particularly in rural areas.

According to a report released last month by the World Health Organization (WHO) and the United Nations Children's Fund (UNICEF), China contributed an estimated 457 million people to the 2 billion who by 2010 had access to improved water sources.

However, these 'improved' sources (a piped supply or borehole, for example, as opposed to a stream or unprotected well) do not always supply safe water, as judged by China's national standards for water quality.

Although $85 \%$ of China's rural population (605 million people) had access to improved water sources in 2010, only around one-quarter of these sources would be considered safe by national standards (R. Zhang et al. J. Environ. Health 26, 3-5; 2009). By comparison with 1990 figures, this implies that only about 35 million people in rural China had gained access to safe water by 2010 . For piped urban water, however, almost 91\% of the water supply complied with chemical and microbial standards (J. Zhang et al. J. Shenyang Agric. Univ. 34, 460-463; 2003), so roughly 295 million urban Chinese gained access to safe water over the same period.

The total Chinese population with access to safe water is therefore 330 million at most. This is about 127 million fewer people than estimated by the WHO/UNICEF report, a figure that is roughly equivalent to the population of Japan.

Hong Yang, Jim A. Wright University of Southampton, UK. hongyanghy@gmail.com

Stephen W. Gundry University of Bristol, UK.

\section{Soil remedies for small-scale farming}

In considering how best to improve poor agricultural soils in parts of Africa and improve crop productivity (Nature 483, 525-527; 2012), microdosing would be a practical and inexpensive way to balance soil nutrients.

Developing countries tend routinely to use fertilizers containing only nitrogen, but a balanced supply of nutrients is essential for a crop to flourish. Urea application doubled in Africa during 1975-2005, causing an increase in the ratio of applied nitrogen to phosphorus and potassium (see go.nature.com/eanpxq). Although urea is cheap and its use is tempting to poor farmers in need of a rapid return on investment, it selectively depletes soil phosphorus, potassium and micronutrients. Ultimately, this imbalance will render the nitrogen ineffective.

Micro-dosing soil with small quantities of correctly proportioned 'NPK' fertilizer would significantly increase crop yields for smallholder farmers who are unable to afford large-scale applications. This simple technique involves dispensing measured amounts of the fertilizer using a bottle cap, for example, into planting holes during sowing. The returns will more than justify the small investment.

Marijn van der Velde, Linda See, Steffen Fritz International Institute for Applied Systems Analysis, Laxenburg, Austria.

velde@iiasa.ac.at

\section{Getting a handle on biological data}

We invite interested parties to help establish an infrastructure to improve the accessibility of the ever-increasing volumes of biological data. Our objective is to prepare a white paper this autumn for consideration by the European Commission's Horizon 2020 funding call in 2013, among others.

New paradigms are needed to manage and process biological data. Good metadata descriptions for each data set will help users to locate the required facts and to make the best use of biological information.

Other infrastructural projects already exist, including the International Nucleotide Sequence Database Collaboration, the Catalogue of Life and the Global Biodiversity Information Facility, but they do not yet enable access to the broad swathes of data currently available.

Members of the community who are involved in generating and using biological data need to establish priorities so that funders can then make targeted grant calls, similar to the ten-year programme reviews established in the physical sciences.

We have initiated a community consultation as an open document (see go.nature. com/tma6gm) that describes a series of topics. Volunteers are invited to open similar documents for each topic, or to create a new topic, by adding their name and the document URL to the main index. A public meeting on the initiative will be held in Brussels on 17 July this year.

Dave Roberts The Natural History Museum, London, UK. dmr@nomencurator.org Alex Hardisty Cardiff University, Cardiff, UK.

\section{CONTRIBUTIONS}

Correspondence may be sent to correspondence@ nature.com after consulting the author guidelines at http://go.nature.com/ cmchno. Alternatively, readers may comment online: www.nature.com/ nature. 